\title{
UPAYA PROMOTIF DAN PREVENTIF KESEHATAN JIWA MELALUI DETEKSI DINI BERBASIS WEB
}

\author{
Evin Novianti*, Duma Lumban Tobing' Bayu Wibisono \\ Program Studi Profesi Ners dan S1 Keperawatan, Fakultas Ilmu Kesehatan, Universitas Pembangunan Nasional \\ "Veteran" Jakarta, Jalan RS Fatmawati, Pangkalan Jati, Kec. Cinere, Kota Jakarta Selatan, Indonesia 12345 \\ *evinnovianti@upnvj.ac.id
}

\begin{abstract}
ABSTRAK
Kader merupakan tenaga potensial di masyarakat yang memiliki peranan penting dalam meningkatkan kesehatan jiwa masyarkat. Perberdayaan kader kesehatan jiwa dapat dilakukan dengan memberikan pelatihan deteksi dini berbasis web agar kader memiliki pemahaman tentang masalah kesehatan jiwa, mendeteksi dini ganggguan jiwa dan melakukan rujukan puskesmas. Penelitian ini bertujuan untuk menganalisis efektifitas pelatihan deteksi dini berbasis web dalam upaya promotif dan preventif kesehatan jiwa. Desain Quasi experiment pre and post test without control group" dengan intervensi pelatihan deteksi dini berbasis web digunakan dalam penelitian ini. Sampel penelitian ini terdiri dari 18 orang kader kesehatan yang diambil dengan menggunakan teknik purposive sampling. Analisa data dilakukan dengan membandingkan data sebelum dan sesudah mendapatkan pelatihan deteksi dini berbasis web terhadap kemampuan kognitif dan psikomotor dengan menggunakan uji statistik paired ttest. Hasil penelitian menunjukkan adanya perubahan kemampuan kognitif dan psikomotor yang signifikan $\mathrm{p}$ value $0,000(\mathrm{p}<0,05)$. Salah satu upaya promotif dan preventif kesehatan jiwa dapat dilakukan melaui deteksi dini berbasis web.
\end{abstract}

Kata kunci: deteksi dini, kader, kesehatan jiwa

\section{PROMOTIVE AND PREVENTIVE EFFORTS FOR MENTAL HEALTH THROUGH WEB-BASED DETECTION EARLY}

\begin{abstract}
Cadres are potential workers in the community who have an important role in improving the mental health of the community. Empowerment of mental health cadres can be done by providing web-based early detection training so that cadres have an understanding of mental health problems, early detection of mental disorders and make a referral of health centers. This study aims to analyze the effectiveness of web-based early detection training in mental health promotion and prevention efforts. Quasi-experiment design pre and post-test without control group "with a web-based early detection training intervention used in this study. The sample of this study consisted of 18 health cadres taken using a purposive sampling technique. Data analysis was performed by comparing data before and after getting web-based early detection training on cognitive and psychomotor abilities using a paired t-test statistical test.The results showed a significant change in cognitive and psychomotor abilities, $\mathrm{p}$ value 0,000 ( $p<0.05$. One of the promotive and preventive efforts of mental health can be done through web-based early detection.
\end{abstract}

Keywords: early detection, cadres, mental health

\section{PENDAHULUAN}

Masalah kesehatan menjadi salah satu fokus kesehatan yang harus segera ditangani oleh pemerintah Indonesia. Masalah kesehatan jiwa yang paling banyak yaitu bipolar sebanyak 60 juta kasus, dimensia sebanyak 47,5 juta kasus, depresi sebanyak 35 juta kasus dan skizofrenia sebanyak 21 juta kasus (Chong et al., 2016). Data Riskesdas (2018) menunjukkan prevalensi gangguan jiwa di Indonesia sebesar 7 permil, artinya per 1.000 rumah tangga terdapat 7 rumah tangga yang memiliki anggota keluarga dengan gangguan jiwa berat (ODGJ). Di provinsi Jawa Barat terjadi peningkatan jumlah ODGJ dari 1,6 permil di tahun 2013 menjadi 5 permil pada tahun 2018 (Balitbangkes, 2018)

Penanganan masalah kesehatan jiwa tidak hanya dilakukan oleh keluarga tapi juga masyarakat karena sebagian besar ODGJ berada di masyarakat. Salah satu upaya penanganan adalah melibatkan kader 
kesehatan jiwa di masyarakat (Astuti. R, Amin.K, 2009).

Seseorang yang yang aktif melakukan penanganan kesehatan pada warga yang mengalami masalah kesehatan jiwa di suatu kelompok masyarakat disebut sebagai kader kesehatan jiwa. Kader berasal dari masyarakat, bekerja dengan sukarela melaksanakan dan mengelola kegiatan kesehatan jiwa di masyarakat (Astuti. R, Amin.K, 2009). Pemberdayaan kader kesehatan jiwa sebagai tenaga potensial yang ada di masyarakat diharapkan mampu mendukung program keperawatan kesehatan jiwa komunitas yang diterapkan di masyarakat (B. A. Keliat, Akemat, Daulima, \& Nurhaeni, 2011).

Fokus pelayanan kesehatan jiwa saat ini lebih ke arah upaya promotif dan preventif kesehatan. Individu yang sehat maupun dengan penyakit kronis menjadi fokus upaya preventif kesehatan jiwa. Upaya tersebut tidak hanya dilakukan oeh tenaga kesehatan namun juga menjadi tanggung jawab masyarakat. Maka dari itu perlu pemberdayaan masyarakat di mulai dari menanamkan pengetahuan, kesadaran, perilaku sehat jiwa dan keperdulian terhadap masalah-masalah kesehatan jiwa (Winahayu, Keliat, \& Wardani, 2016).

Upaya promotif dan preventif kesehatan jiwa yang dilakukan dengan tujuan individu yang mengalami gangguan jiwa kembali produktif, individu yang beresiko menjadi sehat kembali dan individu yang sehat tetap sehat. Karena itu pelayanan primer berbasis swadaya masyarakat dibutuhkan untuk mendeteksi secara cepat kondisi kesehatan jiwa agar bisa ditangani secara dini, sehingga jumlah ODGJ tidak semakin bertambah. Hal ini membutuhkan tenaga yang dekat dengan masyarakat sekitar yaitu kader kesehatan. Melalui kader, data konkret mengenai kesehatan jiwa warganya dapat terkumpul dengan baik (Kurniawan \& Sulistyarini, 2017). Tugas kader kesehatan jiwa antara lain : mendeteksi dini gangguan jiwa, melakukan kunjungan rumah, melakukan rujukan dan melakukan pelaporan ke Puskesmas (B.A. Keliat, Novy, \& Pipin, 2011).

Deteksi dini merupakan pelayanan promotif keperawatan di masyarakat, diawali dengan pelatihan kader kesehatan dan deteksi dini oleh kader dengan mendatangi satu persatu Kepala Keluarga. Kegiatan serupa juga pernah dilakukan di wilayah Kabupaten Garut, Aceh, Bogor (Widianti, Efri \& Rafiyah, 2017) Namun kegiatan ini menemui kendala dimana pendokumentasian kegiatan dilakukan secara manual sehingga tidak terekam secara otomatis, jika data tersebut diperlukan.

Studi pendahuluan yang dilakukan di RW 15, RW 03 dan RW 04 didapatkan data bahwa sudah pernah dilakukan pelatihan kader kesehatan jiwa yang diikuti oleh 20 orang kader kesehatan. Hasil deteksi dini didokumentasikan secara manual pada buku deteksi dini kader. Kendala yang dialami adalah adanya buku yang hilang sehingga data yang terkumpul tidak lengkap. Oleh karena itu dibutuhkan suatu program deteksi dini berbasis web yang dapat menyimpan data dengan aman, dapat diakses dimana saja dan kapan saja, privasi data lebih terjaga karena kader sendiri yang bisa mengakses dan mengelola secara penuh akunnya. Pengguna lain tidak akan bisa mengakses akun pengguna lainnya karena untuk mengakses akun diperlukan login username dan password. Penelitian ini bertujuan untuk efektifitas deteksi dini dengan menggunakan aplikasi web dan menganalisis kemampuan kognitif dan psikomotor kader kesehatan jiwa dalam melakukan deteksi dini.

\section{METODE}

Penelitian ini menggunakan desain penelitian "Quasi Eksperimen pre-post without control group" dengan intervensi pelatihan deteksi dini kesehatan jiwa berbasis web. Penelitian ini sudah mendapat persetujuan etik dari komisi etik penelitian kesehatan (KEPK) Fakultas Kedokteran Universitas Pembangnan Nasional Veteran Jakarta (No: B/2128/VIII/2019/KEPK). Teknik sampling yang digunakan adalah purposive sampling dengan besar sampel yang diteliti sebanyak 18 orang kader kesehatan dengan kriteria inklusi meliputi : (1)sudah pernah menjadi kader kesehatan ; (2)bertempat tinggal di RW 15, RW 03 dan RW 04; (3)telah mendapatkan pelatihan deteksi dini kesehatan jiwa; (4)bersedia menjadi partisipan dan menandatangani informed consent.

Teknik pengumpulan data dengan menggunakan angket/kuisioner untuk melihat kemampuan kader dalam melakukan deteksi dini kesehatan jiwa melalui sistem informasi berbasis web. Pretest dilakukan sebelum responden diberikan sedangkan post test dilakukan segera setelah diberikan perlakuan. 
Penelitian ini menggunakan analisa univariat dengan distribusi frekuensi berupa nilai ratarata usia dan pengalaman menjadi kader. Analisis bivariat menggunakan Uji paired t-test untuk mengetahui besarnya pengaruh variabel pelatihan deteksi dini berbasis web terhadap kemampuan kognitif dan psikomotor kader.

\section{HASIL}

Hasil penelitian tentang upaya promotif dan preventif kesehatan jiwa melalui deteksi dini berbasis web akan disajikan pada table dibawah ini.

Tabel 1.

Karakteristik kader kesehatan jiwa berdasarkan usia dan pengalaman menjadi kader ( $\mathrm{n}=18)$

\begin{tabular}{lcccc}
\hline Karakteristik & Mean & Median & Sd & Min-Max \\
\hline Usia & 42,34 & 40 & 6,32 & $39-55$ \\
\hline Pengalaman menjadi kader (tahun) & 4,43 & 4 & 4,12 & $1-13$ \\
\hline
\end{tabular}

Tabel 1 dapat dilihat bahwa rata-rata kader berusia 42 tahun dan memiliki pengalaman menjadi kader kesehatan rata-rata 4,43 tahun.

Tabel 2.

Perbedaan kemampuan kognitif dan psikomotor kader sebelum dan sesudah pelatihan deteksi dini berbasis web $(n=18)$

\begin{tabular}{lccc}
\hline Variabel & Pre Mean \pm SD & Post Mean \pm SD & p-value Sig (2-tailed) \\
\hline Kemampuan Kognitif & $54,25 \pm 15,51$ & $90,72 \pm 4,212$ & 0,00 \\
\hline Kemampuan Psikomotor & $62,72 \pm 2,421$ & $75,00 \pm 3,757$ & 0,00 \\
\hline
\end{tabular}

Tabel 2 menunjukkan pada $\alpha=0.05$ ada kognitif ini terjadi karena para responden yang perubahan yang bermakna kemampuan kognitif dan kemampuan psikomotor sebelum dan sesudah diberikan intervensi deteksi dini berbasis web.

\section{PEMBAHASAN}

Rata-rata usia responden adalah 42,34 tahun yang tergolong dalam usia dewasa pertengahan. Salah satu karakteristik kelompok usia ini adalah memiliki kemampuan berpikir dan kematangan emosional yang baik sehingga mereka akan lebih perduli dengan permasalahan yang ada disekitarnya. (Wawan \& Dewi, 2010). Hasil penelitian sejalan dengan penelitian yang dilakukan oleh Sukandar, Faiqoh, \& Effendi (2019) dimana usia kader terbanyak berada dalam rentang usia 40-49 tahun. Rata-rata pengalaman menjadi kader kesehatan dalam penelitian ini adalah 4,43 tahun. Pengalaman tersebut akan memudahkan kader dalam mengikuti pelatihan. Hasil penelitian ini didukung oleh penelitian yang dilakukan Mamuroh, Lilis, Witdiawati (2018) yang menyatakan pengalaman lama menjadi kader adalah 1-5 tahun.

Penelitian ini menunjukkan adanya peningkatan kemampuan kognitif (pengetahuan) dan kemampuan psikomotor sesudah diberikan pelatihan deteksi dini berbasis web. Peningkatan kemampuan terlibat sudah pernah mendapatkan pelatihan deteksi dini kader kesehatan jiwa. Hasil penelitian ini didukung oleh penelitian yang dilakukan oleh Rinawan, Susanti, \& Fitri (2018) dimana terdapat peningkatan pengetahuan kader kesehatan dari katagori cukup 45,4\% menjadi baik $100 \%$.

Pengetahuan kader mengenai gangguan jiwa merupakan hal yang penting dalam memberikan pelayanan kesehatan jiwa di masyarakat, terutama dalam upaya pencegahan, penanggulangan, serta dalam proses perawatan pasien gangguan jiwa. Pengetahuan juga menjadi dasar seorang kader untuk melakukan tindakan mengenai permasalahan gangguan jiwa di masyarakat. Pengetahuan kader akan kesehatan jiwa diperoleh melalui pelatihan deteksi dini kesehatan jiwa. Pelatihan kader kesehatan adalah satu upaya untuk peningkatan kemampuan kader tidak hanya kognitif tapi juga dalam segi afektif dan psikomotor. Pelatihan ini akan meningkatkan kader dalam membantu perawatan pada pasien gangguan jiwa dan mengubah stigma negatif masyarakat tentang gangguan jiwa

Upaya dalam mengembangkan peran dan tugasnya dipengaruhi oleh informasi yang didapatkan baik dalam bentuk teori maupun praktik. Sesuai dengan penelitian yang 
dilakukan oleh Sahriana (2018) bahwa kualitas kader dapat tercapai dengan baik melalui peningkatan pengetahuan atau pelatihan secara kontinue. Pelatihan ini dapat juga sebagai refreshing dan saling bertukar pengalaman antar kader.

Pelatihan deteksi dini awal diberikan pemaparan materi tentang cara deteksi dini, mulai dari bagaimana cara berkomunikasi dengan anggota keluarga, bagaimana cara mengkaji, melihat kesesuaian gejala yang ditampilkan pasien dan menggolongkan pasien tersebut dalan kelompok sehat, resiko ataupun gangguan. Selain itu, para kader diberikan kesempatan untuk melakukan role play (bermain peran) cara melakukan deteksi dini. Role play dilakukan bergantian dengan peran sebagai kader, keluarga dan pasien. Dengan demikian diharapkan kader akan lebih percaya diri ketika melakukan kunjungan rumah. Modul pelatihan dan buku pegangan kader juga diberikan guna meningkatkan kemampuan dalam memberikan pelayanan terhadap masyarakat.

Intervensi yang diberikan dalam penelitian ini adalah melakukan deteksi dini dan mendokumentasikan dalam isian tools yang ada dalam web. Pengetahuan yang didapat dari pelatihan awal memudahkan kader untuk memahami isian setiap tools yang ada dalam web. Hasil penelitian ini didukung oleh penelitian yang dilakukan Sutarjo, Prabandari, \& Iravati (2016) yang menyatakan bahwa kemampuan kinerja kader meningkat seiring dengan meningkatnya pengetahuan yang diberikan.

Selain faktor pengetahuan, peneliti menganalisa bahwa pekerjaan mempengaruhi kinerja kader. Sebagian besar responden adalah ibu rumah tangga dan mempunyai waktu lebih banyak sehingga lebih aktif dalam menjalani peran dan tugasnya sebagai kader. Hasil penelitian ini didukung dengan penelitian yang dilakukan Sutisna et al., (2012).

Kinerja kader dapat menjadi harga yang sangat bermanfaat bagi Kelurahan Limo untuk program kesehatan mental masyarakat. Sebuah program pelatihan diindikasikan untuk memperluas kegunaan dan penghargaan bagi kader. Pelatihan harus mencakup bahan yang relevan dengan daerah di mana kader tersebut bekerja dan juga harus digunakan sebagai penilaian sumber daya yang dibawa ke program oleh para kader. Kader harus secara aktif berpartisipasi dalam perencanaan program kesehatan mental masyarakat. Ada beberapa indikasi bahwa komunikasi antara kader dan masyarakat lebih efektif dari pada perawat di masyarakat. Waktu perawat dapat lebih berguna dalam pengawasan dan pelatihan kader.

Adanya peran kader dan keluarga dapat menurunkan tanda dan gejala serta peningkatan kemampuan berupa pasien mampu berpikir rasional, mampu melakukan kegiatan sehari-hari di dalam rumah dan mampu berkomunikasi dengan orang lain dengan motivasi. Peran kader adalah kader memotivasi pasien untuk teratur berobat, memberikan penjelasan kepada keluarga untuk mengawasi pengobatan pasien, memotivasi pasien dan keluarga untuk mengikuti kegiatan kelompok maupun penyuluhan kesehatan serta menganjurkan pasien untuk teratur melakukan pemeriksaan ke puskesmas (Sahriana, 2018).

Pasien dan keluarga yang dikunjungi oleh kader, mereka mendapatkan informasi bahwa pengobatan mudah dan murah didapat. Selain itu dengan mendapatkan penjelasan dari kader, pasien dan keluarga dapat lebih memahami manfaat dari pengobatan dan perawatan, sehingga termotivasi untuk teratur menjalani pengobatan dan perawatan. Setelah para kader kesehatan jiwa sudah dapat membedakan ciriciri individu sehat jiwa, ciri-ciri individu yang resiko terkena gangguang jiwa dan ciri-ciri gangguan jiwa itu sendiri, dilanjutkan dengan pelatihan deteksi dini dengan menggunakan aplikasi web.

Tujuan aplikasi web ini adalah untuk mempermudah tugas dari para kader dan meningkatkan komunikasi antara kader, tokoh masyakat dan puskesmas sebagai tindak lanjut berikutnya. Pembuatan aplikasi web deteksi dini ini tidaklah mudah, karena memerlukan perancangan yang berulang-ulang sehingga siap untuk diberikan ke kader. Kendala lain yang ditemukan adalah tidak semua kader memiliki handphone android dengan memori yang cukup banyak karena akan mempengaruhi kecepatan dalam melakukan deteksi dini. Faktor ketersediaan jaringan juga berpengaruh dalam proses pelatihan ini sehingga dalam pelaksnaannya masih dibantu dengan penggunaan wifi dari pelatih. 


\section{SIMPULAN}

Kemampuan kognitif dan psikomotor kader meningkat setelah diberikan pelatihan deteksi dini berbasis web mengalami peningkatan. Artinya pelatihan deteksi dini berbasis web efektif unttuk meningkatkan kemampuan kognitif dan psikomotor kader. Selain itu dokumentasi hasil deteksi dini yang dimasukkan dalam web akan memudahkan kader dalam pencarian data.

\section{DAFTAR PUSTAKA}

Astuti. R, Amin.K, P. . (2009). Pengaruh Pelatihan Kader Terhadap Peningkatan Pengetahuan Perawatan Pada Gangguan Jiwa Di Wilayah Puskesmas Sawangan Kabupaten Magelang, 14-21.

Balitbangkes, R. I. (2018). Hasil Utama Riskesdas 2018. Kementrian Kesehatan Republik Indonesia, Jakarta.

Chong, H. Y., Teoh, S. L., Wu, D. B.-C., Kotirum, S., Chiou, C.-F., \& Chaiyakunapruk, N. (2016). Global economic burden of schizophrenia: a systematic review. Neuropsychiatric Disease and Treatment, 12, 357.

Keliat, B. A., Akemat, S., Daulima, N. H. C., \& Nurhaeni, H. (2011). Keperawatan kesehatan jiwa komunitas: CMHN (Basic Course). Jakarta: EGC.

Keliat, B. D., Novy, H. C., \& Pipin, F. (2011). Manajemen keperawatan Psikososial dan Kader Kesehatan Jiwa. Jakarta EGC.

Kurniawan, Y., \& Sulistyarini, I. (2017). Jurnal Psikologi dan Kesehatan Mental Komunitas SEHATI ( Sehat Jiwa dan Hati ) Sebagai Intervensi Kesehatan Mental Berbasis Masyarakat. https://doi.org/10.20473/JPKM.v1i2201 6.112-124

Mamuroh, Lilis, Witdiawati, S. (2018). Penguatan Kapasitas Kader Kesehatan dalam Upaya Meningkatkan Dukungan Sosial Berbasis Masyarakat terhadap Klien Kanker Payudara Pendahuluan Kanker payudara merupakan kanker paling umum pada wanita di seluruh dunia , dengan hampir 1, 7 juta kasus baru did. Media Karya Kesehatan, 1(1), $1-10$.

Rinawan, F. R., Susanti, A. I., \& Fitri, H. N. (2018). Perbedaan Pengetahuan Kader Posyandu Sebelum dan Sesudah Dilakukan Pelatihan Penggunaan Aplikasi iPOSYANDU. Jurnal Pengabdian Dan Pengembangan Masyarakat UGM, 1 (2), 143-150.

Sahriana, N. I. M. (2018). Peran Kader Kesehatan Jiwa Dalam Program Kesehatan Jiwa Komunitas Di Masyarakat. Universitas Airlangga, Tesis Tidak Dipublikasikan.

Sukandar, H., Faiqoh, R., \& Effendi, J. S. (2019). Hubungan Karakteristik terhadap Tingkat Aktivitas Kader Posyandu Kecamatan Soreang Kabupaten Bandung. Jurnal Sistim Kesehatan , UNPAD, 4 (3), 102-109.

Sutarjo, P., Prabandari, Y. S., \& Iravati, S. (2016). Pengaruh pelatihan community mental health nursing pada self efficacy dan keterampilan kader kesehatan jiwa. Berita Kedokteran Masyarakat (BKM Journal of Community Medicine and Public Health), Volume 32(2), 67-72.

Sutisna, E., Ravik, S., Bhisma, K., Drajat, M., Kartono, T., Rifai, W., ... Kemenkes, P. (2012). Model Pemberdayaan Masyarakat Bidang Kesehatan , Studi Program Desa Siaga Community Empowerment Model in Health Sector, Study on Village Preparadness Program. Jurnal Kesehatan Masyarakat Nasional, Vol. 7, No, 186-192.

Wawan, A., \& Dewi, M. (2010). Teori dan pengukuran pengetahuan, sikap dan perilaku manusia. Yogyakarta: Nuha Medika, 11-18.

Widianti, Efri \& Rafiyah, I. (2017). Pemberdayaan Masyarakat Dalam Pelaksanaan Deteksi Dini Permasalahan Kesehatan Jiwa di Desa Jayaraga Kecamatan Tarogong Kidul Kabupaten Garut. Jurnal Pengabdian Kepada Masyarakat, Vol. 1(3), 191-195.

Winahayu, E., Keliat, B. A., \& Wardani, I. Y. (2016). Sustainability Factor Related with the Implementation of Community 
Jurnal Keperawatan Jiwa Volume 8 No 1 Hal 69 - 74, Februari 2020

FIKKes Universitas Muhammadiyah Semarang bekerjasama dengan PPNI Jawa Tengah

Mental Health Nursing (CMHN) in South and West Jakarta. Jurnal Ners, 9(2), 305-312. 